Open Access

\title{
The notch pathway promotes NF-KB activation through Asb2 in T cell acute lymphoblastic leukemia cells
}

\author{
Wei Wu ${ }^{1 *}$ Li Nie' ${ }^{2}$ Li Zhang ${ }^{3}$ and Yan Li ${ }^{1^{*}}$
}

\author{
* Correspondence: \\ wuwei_vivi2005@126.com; yanlitf@ \\ yahoo.com.cn \\ 'Department of Clinical Laboratory, \\ Renmin Hospital of Wuhan \\ University, Wuhan 430060, People's \\ Republic of China \\ Full list of author information is \\ available at the end of the article
}

\begin{abstract}
Background: Oncogenic Notch1 is known to activate the NF-kB pathway in T cell acute lymphoblastic leukemia (T-ALL) and to up-regulate the transcription of Asb2a, a specificity factor for an E3 ubiquitin ligase complex that plays an important role in hematopoietic differentiation. Therefore, we hypothesize that Notch1 might regulate the NF-kB pathway through Asb2a.

Methods: The study involved down-regulation of Notch1 in T-ALL cell lines (CCRFCEM cells and MOLT-4 cells) through treatment with gamma-secretase inhibitor (GSI) as well as the modulation of Asb2 in CCRF-CEM cells and MOLT-4 cells through transduction with lentivirus carrying Asb2 or Asb2-shRNA. Experiments using real-time $P C R$, western blot and co-immunoprecipitation were performed to evaluate the expression levels of related genes. Cell proliferation and apoptosis were measured while the expression of Asb2 was enhanced or inhibited.

Results: Here, we demonstrated for the first time that Notch1 can activate the transcription of Asb2a, which then stimulates activation of NF-KB in T-ALL cells. Asb2a exerts its effects by inducing degradation and dissociation of IKBa from NF-kB in T-ALL cells. Moreover, specific suppression of Asb2a expression can promote apoptosis and inhibit proliferation of T-ALL cells.

Conclusion: Notch1 modulates the NF-KB pathway through Asb2a, indicating that Asb2a inhibition is a promising option for targeted therapy against T-ALL.

Keywords: Notch1, NF-kB, Asb2, T cell acute lymphoblastic leukemia
\end{abstract}

\section{Background}

The NF- $\mathrm{KB}$ protein functions as a transcription factor that mediates a broad range of biological processes, including cell survival, proliferation and differentiation [1]. In the

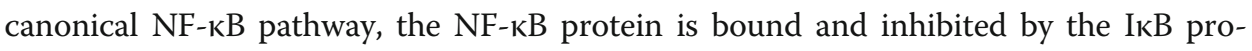
tein. Once a stimulus, such as a pro-inflammatory cytokine, activates the IкB kinase (IKK) complex, the ІкB protein becomes phosphorylated, targeting it for ubiquitination and proteasomal degradation. The degradation of ІкB leads to the release and nuclear translocation of NF- $\mathrm{kB}$, thus inducing the transcriptional activation of its downstream

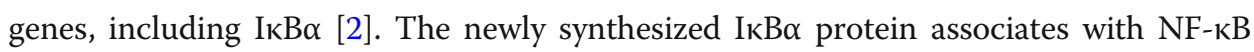
and rapidly shuts down the NF- $\mathrm{kB}$ response, ensuring that the expression of $\mathrm{NF}-\kappa \mathrm{B}$-induced genes is transient [3].

(c) The Author(s). 2018 Open Access This article is distributed under the terms of the Creative Commons Attribution 4.0 International License (http://creativecommons.org/licenses/by/4.0/), which permits unrestricted use, distribution, and reproduction in any medium, provided you give appropriate credit to the original author(s) and the source, provide a link to the Creative Commons license, and indicate if changes were made. The Creative Commons Public Domain Dedication waiver (http://creativecommons.org/ publicdomain/zero/1.0/) applies to the data made available in this article, unless otherwise stated. 
Considering its role in cell survival and proliferation, abnormal or uncontrolled activation of NF- $\mathrm{KB}$ is frequently encountered in several lymphoid malignancies and solid tumors [4-7]. Therefore, NF- $\mathrm{kB}$ regulation has been intensely studied in the context of oncogenesis, and it represents a promising target for cancer therapy. Some research groups have revealed a link between Notch and NF- $\mathrm{BB}$ in human T-ALL and in a mouse model of $\mathrm{T}$ cell leukemia [8-10]. It is well established that abnormal activation of Notch signaling is able to augment the activation of NF- $\mathrm{kB}$. However, the underlying mechanism remains unclear. Notch receptors act as membrane-tethered transcription factors. Upon the binding of its ligands, two successive proteolytic cleavages of the receptor occur to release the intracellular domain of Notch (ICN). The ICN then translocates into the nucleus to initiate the transcription of a number of target genes by interacting with its DNA-binding partner, CSL, and recruiting transcriptional co-activators such as mastermind [11-13]. Among the known downstream target genes of the Notch signaling pathway, the ankyrin repeat-containing protein with a suppressor of cytokine signaling box $2(A s b 2)$ gene is of particular interest due to its vital function in hematopoietic differentiation. Moreover, some studies have shown that Notch signaling initiates the degradation of Jak2, Jak3 and E2A proteins by up-regulating the expression of Asb2 [14, 15]. As the specificity subunit of an E3 ubiquitin ligase complex, the classic function of the Asb2 protein is to target certain proteins for ubiquitination and degradation by the proteasome $[16,17]$. The $A s b 2$ gene encodes two different isoforms, Asb2 $\alpha$ and Asb2 $\beta$, which are involved in hematopoietic differentiation and myogenic differentiation, respectively $[16,18]$. Asb $2 \alpha$ proteins were first identified in retinoic acid-induced acute promyelocytic leukemia (APL) cells [19]. Recently, expression of Asb2 $\alpha$ was observed in normal hematopoietic cells, where it contributes to hematopoiesis [20, 21]. Considering these findings, we hypothesize that Notch signaling may influence NF- $\mathrm{B}$ B activity through the Asb2 $\alpha$ protein in T-ALL cells.

In this report, we show that Notch signaling can up-regulate $A s b 2$ transcription and NF- $\mathrm{kB}$ activation in T-ALL cells. Inhibition of Asb2 $\alpha$ expression can significantly decrease Notch-induced NF- $\mathrm{kB}$ activation, suggesting that Notch signaling mediates $\mathrm{NF}-\mathrm{kB}$ activation through Asb2 $\alpha$. In addition, we explore the mechanism whereby Asb2 $\alpha$ promotes NF- $\mathrm{KB}$ activation. Our results demonstrate that Asb2 $\alpha$ is able to target I $B \alpha$ for destruction and thus is able to free NF- $\mathrm{B}$ from an inhibitory status. Our findings are the first to reveal that Asb2 $\alpha$ is an important regulator between Notch and the NF- $\mathrm{kB}$ signaling pathway in T-ALL cells, indicating that Asb2 $\alpha$ might play a vital role in T-ALL formation and shedding light on a therapeutic target for T-ALL disease.

\section{Methods}

\section{Reagents}

Roswell Park Memorial Institute (RPMI) 1640, Dulbecco's modified Eagle's medium (DMEM) and fetal bovine serum (FBS) were obtained from Invitrogen (Carlsbad, CA, USA). Propidium iodide was obtained from Sigma (Oakville, ON, Canada). FITC-conjugated annexin V was purchased from BD Biosciences (Mississauga, ON, Canada). The Cell Counting Kit-8 (CCK-8) was purchased from Beyotime Institute of Biotechnology (China). DMSO, GSI and MG132 were also purchased from Sigma (Oakville, ON, Canada). 


\section{Cell culture and treatment}

Human embryonic kidney (HEK) 293 cells were cultured in DMEM supplemented with 10\% FBS. The CCRF-CEM human immature $\mathrm{T}$ cell line was obtained from Shanghai Bioleaf Biotech (Shanghai, China). The human leukemia T-cell line (MOLT-4 cells) was purchased from Procell (Wuhan, China). CCRF-CEM and MOLT-4 cells were cultured in RPMI 1640 medium supplemented with $10 \% \mathrm{FBS}$ at $37{ }^{\circ} \mathrm{C}$ in a humidified atmosphere of $5 \% \mathrm{CO}_{2}$ in air. For the chemical treatment experiments, exponentially grown CCRF-CEM cells and MOLT- 4 cells were harvested, resuspended (at $4 \times 10^{5}$ cells $/ \mathrm{ml}$ ) in fresh culture medium and incubated for $24 \mathrm{~h}$ before treatment with $5 \mu \mathrm{M}$ MG132 or $10 \mu \mathrm{M}$ GSI for $24 \mathrm{~h}$. DMSO-treated cells served as the control. For viral infection experiments, exponentially grown CCRF-CEM cells and MOLT-4 cells were harvested, resuspended (at $1 \times 10^{5}$ cells $/ \mathrm{ml}$ ) in fresh culture medium and incubated for $12 \mathrm{~h}$ before being infected with $4 \times 10^{6} \mathrm{TU}$ of lentivirus for $72 \mathrm{~h}$.

\section{Vector construction}

The sequences for the Asb2 shRNA2 were as follows: sense 5'-CAGGCAGGCTGATT AGATATTCAAGAGATATCTAATCAGCCTGCCTGTTTTTTCTCGAGG-3' and antisense 5'-GATCCCTCGAGAAAAAACAGGCAGGCTGATTAGATATCTCTTGAATATC TAATCAGCCTGC CTG-3'. Plasmids pLVX-shRNA2-m and PLVX-mcmv-ZsGreen1 were purchased from Biowit Technologies, Ltd. (China). pLVX-shRNA2-m was first digested with PstI and then filled in with Klenow. The larger fragment was then extracted and cleaved with $B a m H I$. Finally, the $A s b 2$ shRNA oligonucleotides were synthesized, annealed and ligated into the pLVX-shRNA2-m vector to obtain pLVX-shRNA2-hASB2. pCMV-ASB2-HA and Asb2 deletion constructs were kindly provided by Dr. Jay L. Hess (University of Michigan Medical School, Ann Arbor, MI, USA). The full-length HA-tagged hAsb2 sequence was then cloned into the pLVX-mcmv-ZsGreen1 vector through EcoRI and NotI digestion and ligation. The sequences for the Asb2 shRNA1 were as follows: sense 5'-CACCCGAACATCGACGCCTATATTTCAAGACGATA TAGGCGT CGATGTTCG TTTTTTG-3' and antisense 5'-AGCTCAAAAAACGAACATCGACGC CTATATCGTCTTGAAA TATAGGCGTCGATGTTCG-3'. The sequences for the Asb2 shRNA3 were as follows: sense 5'-CACCGGCTGATTAGATACCTGAA TTCAAGACG TTCAGGTATCTAATCAGCCTTTTTTG-3' and antisense 5'AGCTC AAAAAAGGC TGATTAGATACCTGA ACGTCTTGAATTCAGGTATCTAATCAGCC-3’.

\section{Lentivirus packaging and production}

The 293 T cell line was used to obtain lentivirus from packaging plasmids and the lentiviral vector. Approximately $24 \mathrm{~h}$ before transfection, 6-8 $\times 10^{6} 293 \mathrm{~T}$ cells were seeded in $10-\mathrm{cm}$ tissue culture plates in $10 \mathrm{ml}$ of growth medium and then incubated at $37{ }^{\circ} \mathrm{C}$ with $5 \% \mathrm{CO}_{2}$ overnight. The cells were $80-90 \%$ confluent at the time of transfection. Approximately 2-4 h before transfection, the medium was replaced with $5 \mathrm{ml}$ of fresh complete growth medium. The $293 \mathrm{~T}$ cells were transfected with a highly efficient transfection reagent (Biowit Technologies, Ltd.) according to the manufacturer's instructions. Approximately $12-16 \mathrm{~h}$ after transfection, the transfection medium was replaced with $10 \mathrm{ml}$ of fresh complete growth medium, and the cells were incubated at 
$37^{\circ} \mathrm{C}$ for an additional $48 \mathrm{~h}$. The cells were then harvested, and the lentiviral supernatant was filtered through a $0.45-\mu \mathrm{m}$ low-protein-binding filter to remove cellular debris.

Immunoprecipitation

HEK293 cells were lysed with Cell Lysis Buffer for Western and IP (Beyotime) at $4{ }^{\circ} \mathrm{C}$ for $15 \mathrm{~min}$. The cell extracts were incubated with anti-HA antibody (1:5000) overnight at $4{ }^{\circ} \mathrm{C}$. Agarose affinity beads were then added and incubated with the extracts for $1 \mathrm{~h}$ at room temperature. The beads were washed 3 times with RIPA buffer (1\% Nonidet P-40, $0.5 \%$ sodium deoxycholate, and $0.1 \%$ sodium dodecyl sulfate [SDS] in phosphate-buffered saline [PBS]). Proteins were eluted by boiling in SDS loading buffer, resolved by SDS-polyacrylamide gel electrophoresis (PAGE), and detected by Western blot. The primary antibody directed against the HA tag was obtained from Santa Cruz.

\section{Immunoblot analysis}

The cells were lysed in Cell Lysis Buffer for Western and IP (Beyotime) and incubated at $4{ }^{\circ} \mathrm{C}$ for $15 \mathrm{~min}$. Protein extracts were separated by SDS-PAGE and then transferred to polyvinylidene fluoride membranes before overnight incubation with primary antibodies directed against Asb2 (Santa Cruz), ІкB $\alpha$ (Cell Signaling Technology, 1:600 dilution), NF-kB-p65 (BioWorld), Caspase 3 (Proteintech Group, 1:2000 dilution), NICD (abcam), Hes1 (abcam), lamin (Wuhan Boster Biological Technology) or GAPDH (Wuhan Boster Biological Technology) at $4{ }^{\circ} \mathrm{C}$. The membrane was washed with $0.1 \%$ Tween-20 in Tris-buffered saline and then incubated with horseradish peroxidase-conjugated anti-rabbit or anti-goat IgG secondary antibody (Wuhan Boster Biological Technology) for $1 \mathrm{~h}$ at room temperature. The immunoreactive bands were visualized using an ECL Western blotting detection kit (Thermo, Waltham, MA, USA) with light-sensitive film.

\section{Real-time quantitative reverse-transcription PCR}

RNA was extracted from cells using TRIzol reagent (Invitrogen), and cDNA was synthesized using a First Strand cDNA Synthesis Kit (Fermentas) according to the manufacturer's instructions. Real-time quantitative reverse-transcription PCR (RT-qPCR) was performed using 2X SYBR Green/Fluorescein qPCR Master Mix (Fermentas) on an ABI 7900 Sequence Detection System (Applied Biosystems). The data were analyzed using the comparative CT method (ABI User Bulletin number 2). The primer sets were as follows: Asb2, forward 5'-CGTGGTGCAGTTCTGTGAGT-3' and reverse 5'-GTGAGCCAGAG GTCTTGGAG-3'; IкB $\alpha$, forward 5'-GCAAAATCCTGACCTGGTGT-3' and reverse 5'-G CTCGTCCTCTGTGAACTCC-3'; Actin, forward 5'-AGCGAGCATCCCCCAAAGTT-3' and reverse 5'-GGGCACGAAGGCTCATCATT-3'.

\section{Cell viability assay (CCK-8 assay)}

Cell viability was determined using a CCK- 8 . Briefly, $5 \times 10^{3}$ CCRF-CEM cells were resuspended in $100 \mu \mathrm{l}$ of RPMI 1640 medium in a 96-well plate. Lentiviruses harboring empty vector, $A s b 2$ or $A s b 2$-shRNA were then incubated with the cells for $72 \mathrm{~h}$. After the cells were infected, $10 \mu \mathrm{l}$ of CCK-8 solution was added to each well, and the 
96-well plate was continuously incubated at $37{ }^{\circ} \mathrm{C}$ for $2.5 \mathrm{~h}$. The OD value for each well was then read at $450 \mathrm{~nm}$ on a microplate reader (Multiskan, Thermo, USA) to determine cell viability. The assay was repeated three times. Cell viability was calculated as follows:

$$
\text { Cell viability }(\%)=\frac{\mathrm{OD}(\text { experiment })-\mathrm{OD}(\text { blank })}{\mathrm{OD}(\text { control })-\mathrm{OD}(\text { blank })} \times 100
$$

\section{Analysis of T-ALL cell apoptosis}

ALL cell apoptosis was detected using an annexin V/propidium iodide (PI) staining assay. Cells $\left(1 \times 10^{6}\right)$ were washed in ice-cold PBS and resuspended in $500 \mu \mathrm{l}$ of annexin $\mathrm{V}$ binding buffer (140 mM NaCl, $2.5 \mathrm{mM} \mathrm{CaCl}_{2}, 1.5 \mathrm{mM} \mathrm{MgCl}_{2}$, and $10 \mathrm{mM}$ HEPES, $\mathrm{pH}$ 7.4) containing annexin V-FITC and PI $(1 \mu \mathrm{g} / \mathrm{ml})$ before being incubated for 30 min at $4{ }^{\circ} \mathrm{C}$. FACS analysis was performed with Cell Quest-Pro software, and cells negative for both annexin V and PI were considered viable.

\section{Statistical analyses}

All the experiments were performed three times. The data are expressed as mean \pm standard deviation (SD). Differences between the control and experimental results were tested by Student's t-test (two-tailed) and one-way analysis of variance (ANOVA). All statistical analyses were carried out using SPSS version 22.0 (SPSS Inc., Chicago, IL, USA) and $p<0.05$ was considered to indicate a significant difference.

\section{Results}

Notch signaling can initiate Asb2 transcription and NF-KB activation in T-ALL cells

Notch signaling can stimulate $A s b 2$ gene transcription in NIH 3 T3 cells (a mouse embryonic fibroblast cell line) and in lymphoid cells [14]. However, whether the same stimulation occurs in T-ALL cells remains unclear. To answer this question, a human $\mathrm{T}$ cell lymphoblast-like cell line (CCRF-CEM) and a human leukemia T-cell line (MOLT-4) were treated with gamma-secretase inhibitor (GSI), which is a Notch-specific inhibitor. Asb2 transcription was significantly decreased $24 \mathrm{~h}$ after GSI treatment of CCRF-CEM cells and MOLT-4 cells (Fig. 1a). This result suggests that activated Notch signaling can up-regulate $A s b 2$ transcription. Notch signaling is known to be constitutively activated, thus inducing NF- $\kappa B$ activation in T-ALL cells [8-10]. To confirm this constitutive behavior, we measured the nuclear NF- $\mathrm{kB}$ levels in CCRF-CEM cells and MOLT-4 cells $24 \mathrm{~h}$ after DMSO or GSI treatment. GSI treatment significantly decreased the amount of NF- $\mathrm{kB}$ in the nuclei of CCRF-CEM cells and MOLT-4 cells, in contrast to DMSO treatment (Fig. 1b).

Notch signaling regulates NF-KB activation by activating Asb2 transcription in T-ALL cells Because Notch signaling can up-regulate $A s b 2$ transcription and NF- $\mathrm{kB}$ activation in T-ALL cells, we investigated whether a relationship between NF- $\mathrm{kB}$ activation and Asb2 expression exists. To test this possibility, 3 Asb2-shRNAs, Asb2-shRNA1, $A s b 2$-shRNA2 and $A s b 2$-shRNA3, were created and then evaluated for their effectiveness (Fig. 2a). The results showed that all of these Asb2-shRNAs could significantly decrease the mRNA level of $A s b 2$. Because $A s b 2$-shRNA2 was the most efficient 


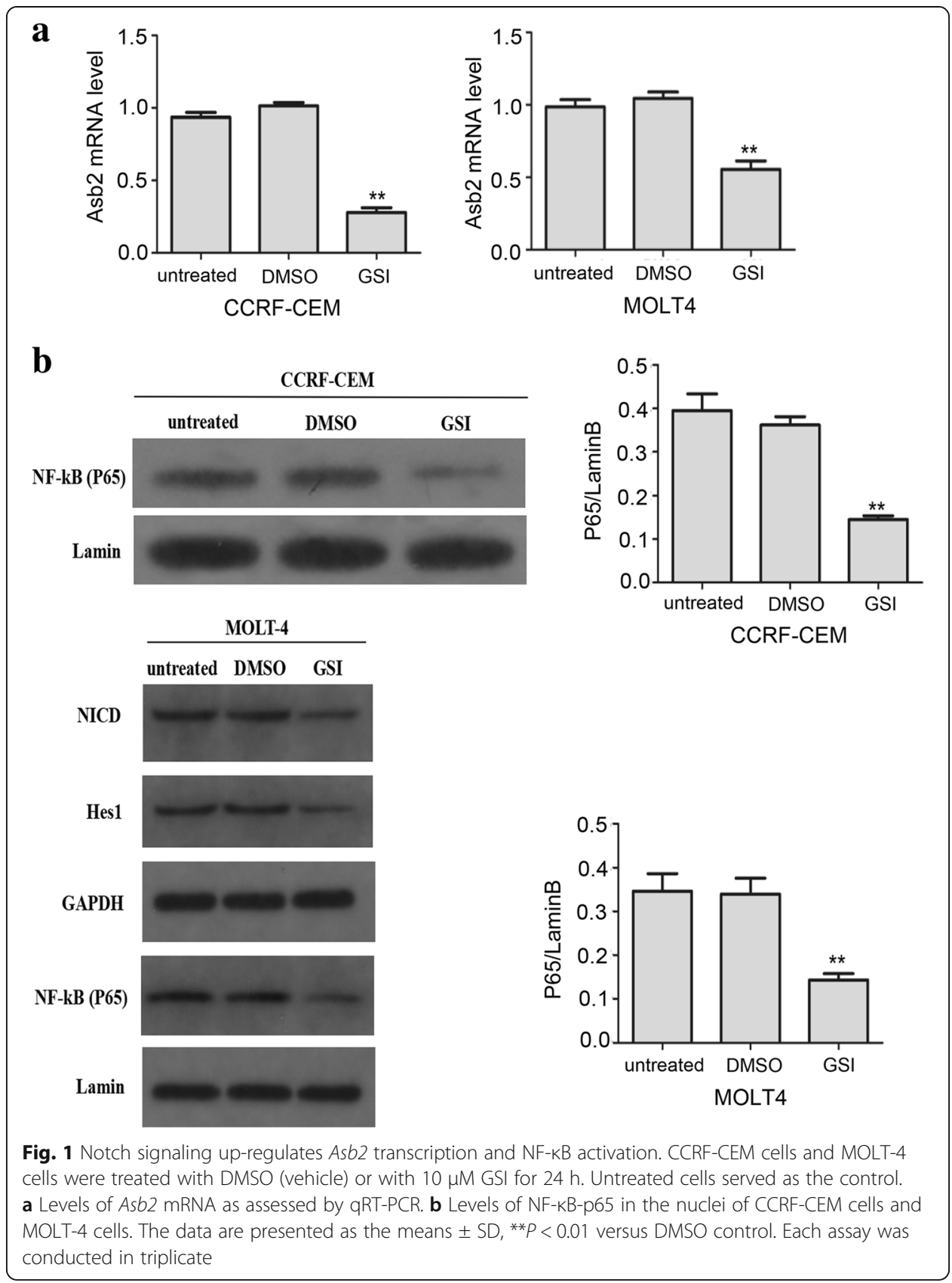

shRNA, CCRF-CEM cells and MOLT- 4 cells were transduced with lentiviruses harboring wild-type $A s b 2, A s b 2$-shRNA2 or empty vector. Compared to the control, the over-expression of wild-type Asb2 enhanced NF-kB activation, whereas knockdown of Asb2 significantly decreased NF- $\mathrm{kB}$ activation (Fig. 2b). These results suggest that Notch signaling regulates NF- $\mathrm{kB}$ activation by activating $A s b 2$ transcription.

\section{Notch signaling stimulates NF-KB activation through Asb2-induced IкBa degradation}

Given that Asb2 regulates some signaling pathways by inducing the degradation of certain proteins, Asb2 likely promotes the degradation of the NF- $\kappa B$ inhibitor IкB $\alpha$ to 


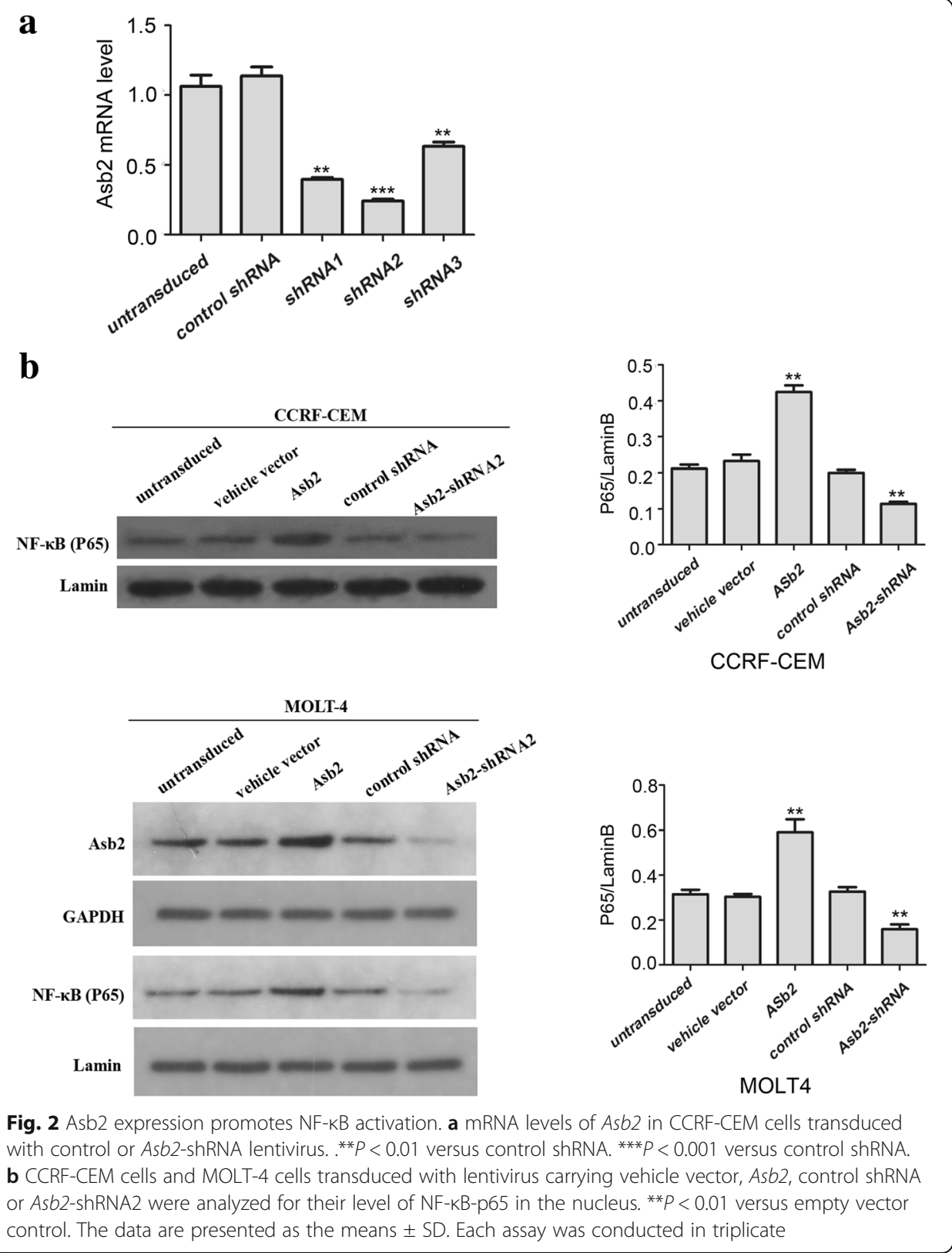

release and thus activate NF- $\mathrm{kB}$. To test this hypothesis, CCRF-CEM cells and MOLT-4 cells were transduced with lentiviruses carrying wild-type Asb2, Asb2-shRNA or empty vector. This experiment demonstrated that the expression of exogenous $A s b 2$ could decrease the protein level of IKB $\alpha$, whereas knockdown of Asb2 could increase

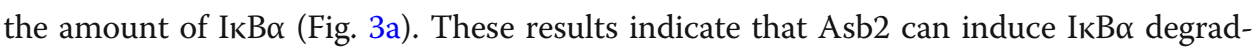
ation and that Notch signaling, as an upstream regulator of Asb2, may initiate NF- $\mathrm{kB}$ activation by indirectly modulating І $\mathrm{\kappa} B \alpha$ degradation. To verify this conclusion, CCRF-CEM cells and MOLT-4 cells were treated with GSI or vehicle (DMSO). Indeed, inhibition of the Notch signaling pathway restored the protein level of IкB $\alpha$ (Fig. 3b). To rule out the possibility that the constitutively active Notch signaling pathway influences the protein level of ІкB $\alpha$ by inhibiting ІкB $\alpha$ transcription, CCRF-CEM cells were 


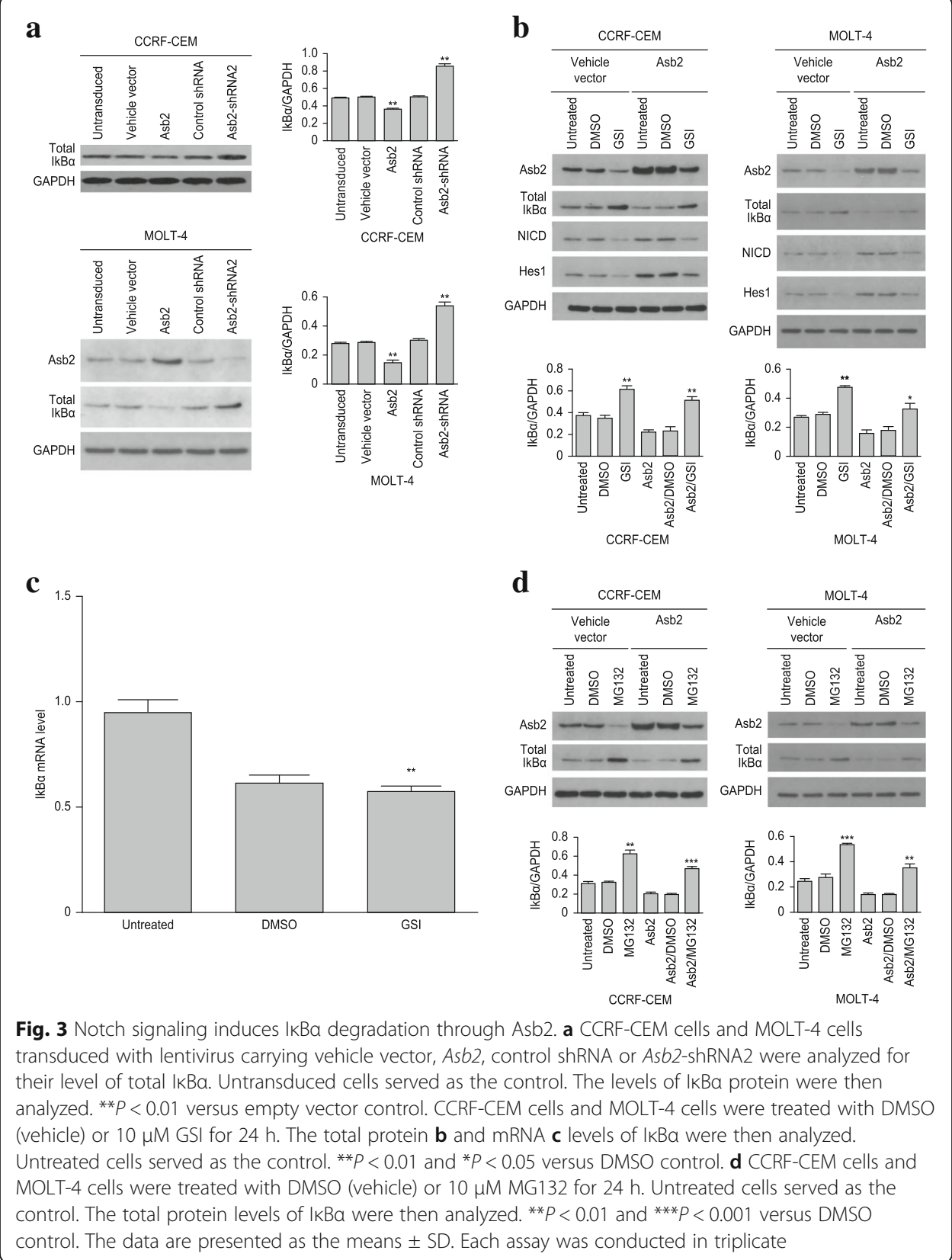

treated with GSI, and the mRNA levels of $\mathrm{I} \kappa \mathrm{B} \alpha$ were then measured. The results showed that blockade of Notch signaling did not increase IкB $\alpha$ transcription (Fig. 3c).

\section{Asb2-induced IKBa degradation is proteasome dependent}

Because Asb2 is known to mediate protein degradation by forming an ECS (Elongin B/ C-Cul2/5-SOCS-box protein) E3 ubiquitin ligase complex, Asb2-induced ІкB $\alpha$ degradation may be proteasome dependent. To verify this hypothesis, CCRF-CEM cells and MOLT-4 cells were treated with the proteasome inhibitor MG132. Proteasome inhibition significantly restored the protein level of IкB $\alpha$ in CCRF-CEM cells and MOLT-4 cells (Fig. 3d), suggesting that Asb2-induced IкB $\alpha$ degradation might depend on the proteasome. 
Both the SOCS box and the region linking the SOCS box to the ankyrin repeats are needed for efficient Asb2 binding

To test whether IкB $\alpha$ physically interacts with Asb2, 293 cells were transfected with HA-tagged Asb2 or with empty vector. A co-immunoprecipitation (co-IP) assay was then performed using an antibody directed against the HA tag. This experiment showed that IкB $\alpha$ was pulled down by HA-tagged full-length Asb2 (Fig. 4), suggesting that $\mathrm{I} \mathrm{B} \alpha \alpha$ can physically bind to $\mathrm{Asb} 2$ and that $\mathrm{I} \mathrm{B} \alpha$ is a substrate of Asb2. Asb2 is composed of a SOCS box and ankyrin repeats $[16,17]$. Previous studies have indicated that the SOCS box of Asb2 is responsible for interacting with the Elongin $\mathrm{BC}$ complex, whereas the ankyrin repeats interact with the substrate of Asb2 [16, 21]. However, one study also demonstrated that Asb2 interacts with Jak2 via sequences outside the ankyrin repeats [14]. Therefore, we asked which region of Asb2 mediates the interaction between Asb2 and IkB $\alpha$. To answer this question, 293 cells were transfected with HA-tagged full-length Asb2, HA-tagged Asb2 mutants or an empty vector. A co-IP assay was then performed using an antibody directed against the HA tag. The deletion of amino acids 456-587 led to disruption of the interaction between IкB $\alpha$ and Asb2 (Fig. 4). A more robust interaction was observed when the SOCS box or the region linking the SOCS box to the ankyrin repeats was included (Fig. 4, compare lanes 3, 4 and 5), suggesting that both the SOCS box and the region linking the SOCS box to the ankyrin repeats are needed for efficient Asb2 binding.

\section{Asb2 expression promotes tumorigenesis of T-ALL cells}

Enhanced activation of NF- $\mathrm{kB}$ results in the occurrence of cancer by promoting cellular proliferation and inhibiting apoptosis [22]. To test whether blocking Asb2 expression can suppress the tumorigenesis of T-ALL cells, CCRF-CEM cells and MOLT-4 cells were transduced with lentiviruses containing wild-type $A s b 2$, Asb2-shRNA or empty vector. MTT assay results demonstrated that the expression of wild-type Asb2 could significantly increase the viability of CCRF-CEM cells, whereas Asb2 knockdown could decrease the viability of CCRF-CEM cells (Fig. 5a). In addition, the expression of wild-type $A s b 2$ led to a lower number of apoptotic CCRF-CEM cells, whereas Asb2 knockdown resulted in an elevated number of apoptotic CCRF-CEM cells through annexin $\mathrm{V}$ binding (Fig. 5b). Consistent with this result, the expression of wild-type Asb2 significantly decreased the expression of cleaved caspase-3, whereas $A s b 2$ knockdown resulted in elevated expression of cleaved caspase-3 in MOLT-4

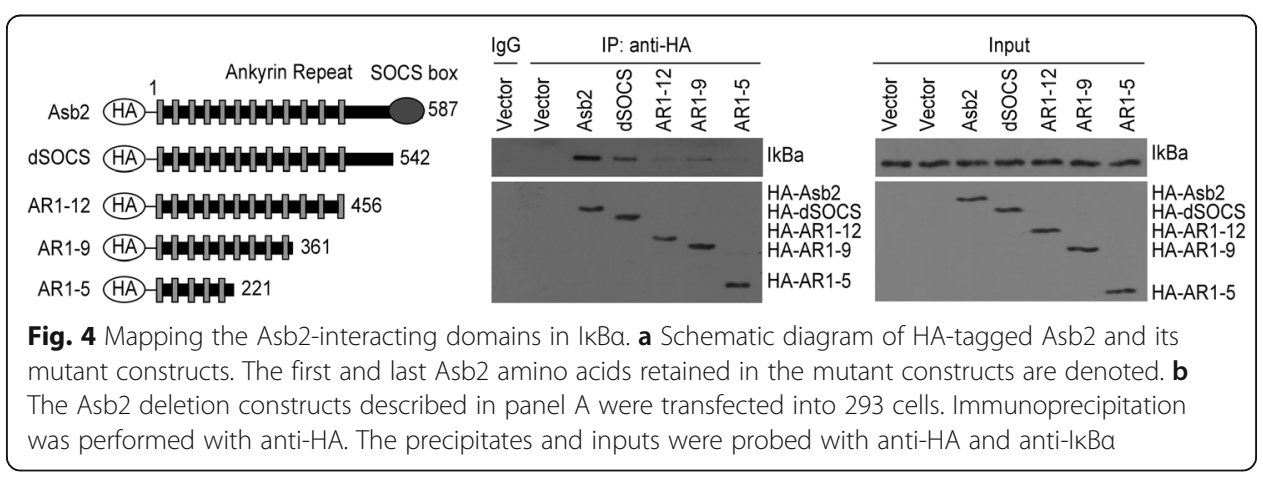




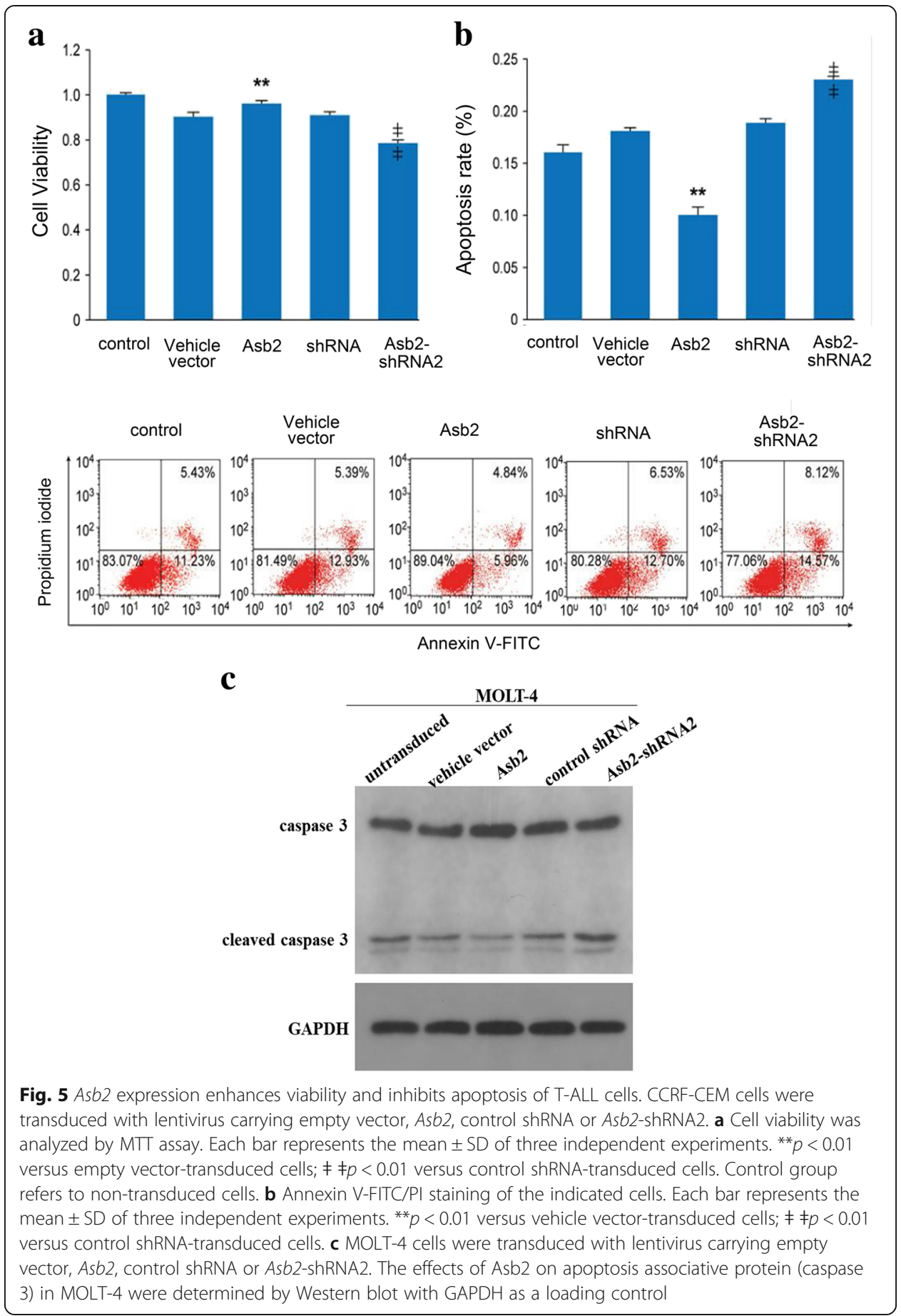

cells (Fig. 5c). These results suggest that Asb2 may be a key regulator whose abnormal expression can cause T-ALL.

\section{Discussion}

A previous study found that Notch stimulates NF- $\mathrm{kB}$ activation by initiating the transcription of Hes1, which then suppresses the expression of CYLD, a negative regulator of IKK activity in T-ALL cells [23]; however, this finding does not rule out the possibility that 
other mechanisms co-exist. Our studies identified a novel mechanism for Notch-induced NF- $\mathrm{kB}$ activation in T-ALL cells. We first showed that Asb2 is a critical mediator of Notch-induced NF-кB activation because it targets ІкB $\alpha$ for degradation.

Asb2 is expressed during all-trans retinoic acid-induced differentiation of promyelocytic cell lines [19]. Asb2 $\alpha$ is also involved in hematopoietic differentiation [21]. Recently, Asb2 $\alpha$ was observed to be expressed in dendritic cells and to play an important role in regulating the migration of immature dendritic cells by targeting the actin-binding protein filamin for degradation [20]. Taken together, these findings suggest that Asb2 $\alpha$ exerts an extensive influence on hematopoiesis. However, no finding has yet indicated that Asb2 plays a role in the formation of T-ALL. Our study is the first to demonstrate that Asb2 is involved in the oncogenesis of T-ALL cells. These findings may lead to the development of new methods to inhibit oncogenic mechanisms that involve the abnormal activation of Notch and NF- $\mathrm{kB}$.

As the substrate-binding subunit of the ECS ligase complex, Asb2 mediates the ubiquitination of certain substrates, such as the actin-binding protein filamin, as well as Jak2, Jak3 and E2A [14, 15, 24-26]. Through these diverse substrates, Asb2 influences a wide range of biological functions. However, many substrates of Asb2 remain to be discovered. Here, we add IKB $\alpha$ to the list of Asb2 substrates, thereby establishing a

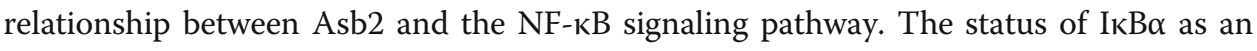
Asb2 substrate indicates that Asb2 may influence specific biological activities by regulating the NF- $\mathrm{kB}$ signaling pathway.

Asb2 belongs to a large protein family that has 18 members in humans [27]. Each of the Asb proteins has a SOCS box at its C-terminus and a variable number of ankyrin repeats at its $\mathrm{N}$-terminus. Therefore, a certain degree of functional redundancy may exist among Asb family members. For example, a previous study showed that Asb1 behaves similarly to Asb2 in promoting E47 and Jak2 degradation [14]. Based on the findings of this study, we suspect that Asb1 may also be able to promote IkB $\alpha$ degradation in T-ALL cells. Thus, Asb1-induced IкB $\alpha$ degradation may be another mechanism that leads to the abnormal activation of NF-kB in T-ALL cells.

\section{Conclusion}

We demonstrated that Notch1 is able to up-regulate the expression of Asb2 $\alpha$ and activate NF-kB in T-ALL cells. Furthermore, we found that Notch1 regulates the NF- $\kappa B$ pathway through Asb2 $\alpha$, which is capable of interacting with ІкB $\alpha$ and then inducing degradation of IкB $\alpha$. We also showed that suppression of Asb2 $\alpha$ expression can promote apoptosis and inhibit proliferation of T-ALL cells, suggesting that Asb2 $\alpha$ may play an important role in the pathogenesis of T-ALL. Taken together, our findings might provide a promising option for targeted therapy against T-ALL.

\footnotetext{
Abbreviations

Asb2: Ankyrin repeat and SOCS box protein 2; IKBa: Nuclear factor of kappa light polypeptide gene enhancer in B-cells inhibitor, alpha; NF-kB: Nuclear factor kappa-light-chain-enhancer of activated B cells; T-ALL: T cell acute lymphoblastic leukemia
} 


\section{Funding}

This work was supported by Grants 81200389 and 81200058 from the National Natural Science Foundation of China (WW, LN), Grant 20120141120077 from the Specialized Research Fund for the Doctoral Program of Higher Education of China (WW) and Grant 2016CFB456 from the Natural Science Foundation of Hubei Province of China (WW).

\section{Authors' contributions}

WW and $Y L$ conceived of the study, acquired, analyzed and interpreted the data, and drafted the manuscript. LN revised the manuscript. LZ approved of the version of the manuscript sent for publication. All authors read and approved the final manuscript.

\section{Ethics approval and consent to participate}

Not applicable.

\section{Consent for publication}

Not applicable.

\section{Competing interests}

The authors declare that they have no conflict of interest.

\section{Publisher's Note}

Springer Nature remains neutral with regard to jurisdictional claims in published maps and institutional affiliations.

\section{Author details}

'Department of Clinical Laboratory, Renmin Hospital of Wuhan University, Wuhan 430060, People's Republic of China.

2Department of Geriatrics, Renmin Hospital of Wuhan University, Wuhan 430060, People's Republic of China.

${ }^{3}$ Department of Hematology, Renmin Hospital of Wuhan University, Wuhan 430060, People's Republic of China.

Received: 28 December 2017 Accepted: 27 July 2018

Published online: 09 August 2018

\section{References}

1. Karin M. Nuclear factor-kappaB in cancer development and progression. Nature. 2006:441:431-6.

2. Vallabhapurapu S, Karin M. Regulation and function of NF-kappaB transcription factors in the immune system. Annu Rev Immunol. 2009;27:693-733.

3. Hoffmann A, Levchenko A, Scott ML, Baltimore D. The IkappaB-NF-kappaB signaling module: temporal control and selective gene activation. Science. 2002:298:1241-5.

4. Davis RE, Brown KD, Siebenlist U, Staudt LM. Constitutive nuclear factor kappaB activity is required for survival of activated B cell-like diffuse large B cell lymphoma cells. J Exp Med. 2001;194:1861-74.

5. Compagno M, Lim WK, Grunn A, Nandula SV, Brahmachary M, Shen Q, et al. Mutations of multiple genes cause deregulation of NF-kappaB in diffuse large B-cell lymphoma. Nature. 2009;459:717-21.

6. Kato M, Sanada M, Kato I, Sato Y, Takita J, Takeuchi K, et al. Frequent inactivation of A20 in B-cell lymphomas. Nature. 2009:459:712-6

7. Meylan E, Dooley AL, Feldser DM, Shen L, Turk E, Ouyang C, et al. Requirement for NF-kappaB signalling in a mouse model of lung adenocarcinoma. Nature. 2009;462:104-7.

8. Screpanti I, Bellavia D, Campese AF, Frati L, Gulino A. Notch, a unifying target in T-cell acute lymphoblastic leukemia? Trends Mol Med. 2003;9:30-5.

9. Shin HM, Minter LM, Cho OH, Gottipati S, Fauq AH, Golde TE, et al. Notch1 augments NF-kappaB activity by facilitating its nuclear retention. EMBO J. 2006;25:129-38.

10. Vilimas T, Mascarenhas J, Palomero T, Mandal M, Buonamici S, Meng F, et al. Targeting the NF-kappaB signaling pathway in Notch1-induced T-cell leukemia. Nat Med. 2007;13:70-7.

11. Tamura K, Taniguchi Y, Minoguchi S, Sakai T, Tun T, Furukawa T, et al. Physical interaction between a novel domain of the receptor notch and the transcription factor RBP-Jkappa/Su(H). Curr Biol. 1995;5:1416-23.

12. Jarriault S, Brou C, Logeat F, Schroeter EH, Kopan R, Israel A. Signalling downstream of activated mammalian notch. Nature. 1995;377:355-8.

13. Wu L, Aster JC, Blacklow SC, Lake R, Artavanis-Tsakonas S, Griffin JD. MAML1, a human homologue of Drosophila mastermind, is a transcriptional co-activator for NOTCH receptors. Nat Genet. 2000:26:484-9.

14. Nie L, Zhao Y, Wu W, Yang YZ, Wang HC, Sun XH. Notch-induced Asb2 expression promotes protein ubiquitination by forming non-canonical E3 ligase complexes. Cell Res. 2011;21:754-69.

15. Wu W, Sun XH. A mechanism underlying NOTCH-induced and ubiquitin-mediated JAK3 degradation. J Biol Chem. 2011:286:41153-62

16. Heuze ML, Guibal FC, Banks CA, Conaway JW, Conaway RC, Cayre YE, et al. Asb2 is an Elongin BC-interacting protein that can assemble with Cullin 5 and Rbx1 to reconstitute an E3 ubiquitin ligase complex. J Biol Chem. 2005:280:5468-74.

17. Kohroki J, Nishiyama T, Nakamura T, Masuho Y. ASB proteins interact with Cullin5 and Rbx2 to form E3 ubiquitin ligase complexes. FEBS Lett. 2005;579:6796-802

18. Bello NF, Lamsoul I, Heuze ML, Metais A, Moreaux G, Calderwood DA, et al. The E3 ubiquitin ligase specificity subunit Asb2beta is a novel regulator of muscle differentiation that targets filamin B to proteasomal degradation. Cell Death Differ. 2009;16:921-32. 
19. Moog-Lutz C, Cave-Riant F, Guibal FC, Breau MA, Di Gioia Y, Couraud PO, et al. JAML, a novel protein with characteristics of a junctional adhesion molecule, is induced during differentiation of myeloid leukemia cells. Blood. 2003;102:3371-8.

20. Lamsoul I, Metais A, Gouot E, Heuze ML, Lennon-Dumenil AM, Moog-Lutz C, et al. Asb2alpha regulates migration of immature dendritic cells. Blood. 2013;122:533-41.

21. Wang J, Muntean AG, Hess JL. ECSASB2 mediates MLL degradation during hematopoietic differentiation. Blood. 2012;119:1151-61.

22. Karin M. NF-kappaB and cancer: mechanisms and targets. Mol Carcinog. 2006:45:355-61.

23. Espinosa L, Cathelin S, D'Altri T, Trimarchi T, Statnikov A, Guiu J, et al. The notch/Hes 1 pathway sustains NF-kappaB activation through CYLD repression in T cell leukemia. Cancer Cell. 2010;18:268-81.

24. Heuze ML, Lamsoul I, Baldassarre M, Lad Y, Leveque S, Razinia Z, et al. Asb2 targets filamins A and B to proteasomal degradation. Blood. 2008;112:5130-40.

25. Burande CF, Heuze ML, Lamsoul I, Monsarrat B, Uttenweiler-Joseph S, Lutz PG. A label-free quantitative proteomics strategy to identify E3 ubiquitin ligase substrates targeted to proteasome degradation. Mol Cell Proteomics. 2009; 8:1719-27

26. Lamsoul I, Burande CF, Razinia Z, Houles TC, Menoret D, Baldassarre M, et al. Functional and structural insights into Asb2a, a novel regulator of integrin-dependent adhesion of hematopoietic cells. J Biol Chem. 2011;286:30571-81.

27. Hilton DJ, Richardson RT, Alexander WS, Viney EM, Willson TA, Sprigg NS, et al. Twenty proteins containing a C-terminal SOCS box form five structural classes. Proc Natl Acad Sci U S A. 1998:95:114-9.

Ready to submit your research? Choose BMC and benefit from:

- fast, convenient online submission

- thorough peer review by experienced researchers in your field

- rapid publication on acceptance

- support for research data, including large and complex data types

- gold Open Access which fosters wider collaboration and increased citations

- maximum visibility for your research: over $100 \mathrm{M}$ website views per year

At $\mathrm{BMC}$, research is always in progress.

Learn more biomedcentral.com/submissions 